\section{Kidney Blood Pressure Research}

Kidney Blood Press Res 2012;36:55-64

\begin{tabular}{l|l}
\hline DOI: $10.1159 / 000339026$ & (c) 2012 S. Karger AG, Basel
\end{tabular}

Published online: August 06, 2012

Accepted: June 22, 2012

\title{
Relationship of Fibroblast Growth Factor 23 with Left Ventricle Mass Index and Coronary Calcificaton in Chronic Renal Disease
}

\author{
Abdulkadir Unsal Sennur Kose Budak Yener Koc Taner Basturk Tamer Sakaci \\ Elbis Ahbap Ayse Sinangil \\ Department of Nephrology, Sisli Etfal research and educational hospital, Istanbul, Turkey
}

\section{Key Words}

FGF-23 • LVMI • Coronary calcification • Chronic kidney disease

\begin{abstract}
Background: to evaluate the relationship between FGF23 and changes in biochemical parameters, left ventricle mass index, coronary, aortic and, valve calcifications. Methods: Totally 185 patients with chronic renal disease were included in this prospective, cross-sectional study. The patients were stratified according to GFR levels $\left(\mathrm{mL} / \mathrm{min} / 1.73 \mathrm{~m}^{2}\right)$ into 5 groups: $\geq 60,45-59,30-44,15-29$ and $<15$ (group 1-5 respectively).Biochemical parameters, serum FGF23 levels were measured. Echocardiographic assessments and Coronary artery calcification (CAC) with multidetector computerized tomography (MDCT) were done, left ventricle muscle mass (LVMI) was measured all patients. Results: Left ventricular hypertrophy (LVH), aortic and valve calcification were detected in $27.8 \%, 25.3 \%$ and $12 \%$ of patients respectively. CAC was detected in 18 patients. LVMI and FGF23 levels were found to increase proportionally with the severity of renal failure. A significant positive correlation between FGF-23 level and serum phosphate, $\log _{\text {Ртн' }}$ and CaxP product was found. While a correlation between FGF-23 and valve calcification was detected, no correlation could be detected with LVMI, LVH, coronary and aortic calcification. Conclusion: In CKD, circulating FGF-23 and LVMI levels gradually increase with declining renal function such that by the time patients reach end-stage renal disease. Correlation between $\log _{\mathrm{FGF} 23}$ and valve calcification was significant, whereas no statistically significant relationship was found between $\log _{\mathrm{FGF} 23}$ and LVMI, LVH, aortic and coronary artery calcifications.
\end{abstract}




\section{Kidney Blood Pressure Research}

\section{Introduction}

Cardiovascular disease is the leading cause of mortality in chronic renal disease and, it is observed 10-30 times more frequently in patients on chronic dialysis in comparison to the general population [1]. Vascular calcification and left ventricle hypertrophy are known to be independent predictors of mortality in chronic renal disease. Any increase in serum phosphate level in chronic renal disease, even within the normal range, was shown to be associated with an increase in cardiovascular events and a progressive decline in renal functions [2-4].

Fibroblast growth factor 23 (FGF23), a phosphoregulatory hormone that increases urinary phosphate excretion and decreases synthesis of 1,25-dihydroxyvitamin $\mathrm{D}(1,25 \mathrm{D})$ and parathyroid hormone (PTH) was shown in some studies to be increased in the early phases of chronic renal disease when hyperphosphatemia is not present $[5,6]$. In recent years, FGF23 was shown to be a risk factor being independent from phosphate and PTH levels and associated with mortality $[7,8]$.

Studies on relationship between the phosphaturic hormone FGF23 and coronary artery calcification, left ventricle hypertrophy and disturbances of calcium - phosphate metabolism and on the prognostic significance of FGF23 still continue. A negative relationship between FGF23 and vascular calcification was found in some studies [9], whereas others report it as a positive and independent risk factor.

We aimed to evaluate the relationship between FGF23 and changes in biochemical parameters, left ventricle mass index, coronary, aortic and, valve calcifications.

\section{Materials and Methods}

Totally 185 patients with chronic renal disease, who were followed-up at the outpatient clinics of Peritoneal Dialysis and Hemodialysis Units of the Department of Nephrology of Sisli Etfal Education and Research Hospital were included in this study.

The study was designed as prospective cross-sectionally. Patients older than 18 years, who were being followed-up for at least 6 months at the nephrology outpatient clinics with renal failure, whose renal functions were stable for at least 3 months, or patients under hemodialysis (HD) or peritoneal dialysis (PD) for at least 6 months were included to the study. All participants gave informed consent.

Patients with history of parathyroid adenoma, parathyroidectomy, coronary heart disease, cardiomyopathy, heart failure, valvular heart disease, malignancy, pregnancy or planning to be pregnant were excluded.

Demographic characteristics such as age, gender, duration of illness and, smoking status were recorded. Comorbidities like diabetes and hypertension were asked, and height and weight of the patients were measured, and body mass index (BMI) values were calculated.

All HD patients were receiving conventional 4 - hr HD with polysulphone dialysers, thrice a week, with bicarbonate dialysate, and standard heparin anticoagulation. Mean blood flow rate was $300 \mathrm{~mL} / \mathrm{min}$ during the HD session (range 250-340 mL/min). Dialysate fluid composition was as follows: sodium $140 \mathrm{mEq} / \mathrm{L}$, potassium 1-3 mEq/L, calcium $3 \mathrm{mEq} / \mathrm{L}$ and bicarbonate $33 \mathrm{mEq} / \mathrm{L}$. Dry weight was considered optimal when the patients had normal blood pressure, no residual symptoms of orthopnea, dyspnea and, edema during the interdialytic period.

All PD patients were receiving solutions containing $1.25 \mathrm{mmol} / \mathrm{dL}$ calcium, $1.36 \%, 2.27 \%, 3.86 \%$ glucose at 8-10 L/day in continuous ambulatory PD (CAPD) treatment. Dry weight was considered optimal when the patients had normal blood pressure, with no residual symptoms of orthopnea, dyspnea and, edema.

Systolic and diastolic blood pressures (BP) of the patients were measured after resting for 10 minutes. Blood pressures were measured with a conventional mercury manometer. Hypertension was defined as patients on antihypertensive medication and/or systolic BP of $140 \mathrm{~mm} \mathrm{Hg}$ or above, diastolic BP of $90 \mathrm{~mm}$ Hg or above [10].

Glomerular filtration rate (GFR) were calculated with Modification of Diet in Renal Disease (MDRD) formula, according to K/DOQI guidelines. [GFR $\left(\mathrm{mL} / \mathrm{min} / 1.73 \mathrm{~m}^{2}\right)=186,3 \times$ (Serum Creatinine) ${ }^{-1.154} \mathrm{x}$ 


\section{Kidney \\ Blood Pressure Research}

Kidney Blood Press Res 2012;36:55-64

\begin{tabular}{l|l}
\hline DOI: $10.1159 / 000339026$ & $\begin{array}{l}\text { C) } 2012 \text { S. Karger AG, Basel } \\
\text { www.karger.com/kbr }\end{array}$ \\
\hline Published online: August 06, 2012 &
\end{tabular}

Published online: August 06, 2012

www.karger.com/kbr

(Age) $)^{-0.203} \times(0.742$ if the patient is female)] was used as the short MDRD formula [11]. The patients were stratified according to GFR levels into 5 groups: those with a GFR value of $\geq 60 \mathrm{~mL} / \mathrm{min} / 1.73 \mathrm{~m} 2$ consisted group 1, patients with a GFR value of $45-59 \mathrm{~mL} / \mathrm{min} / 1.73 \mathrm{~m}^{2}$ consisted group 2, 30-44 mL/min $/ 1.73 \mathrm{~m}^{2}$ group 3, $15-29 \mathrm{~mL} / \mathrm{min} / 1.73 \mathrm{~m}^{2}$ group 4 , and $<15 \mathrm{~mL} / \mathrm{min} / 1.73 \mathrm{~m}^{2}$ (under dialysis therapy) group 5 .

Biochemical tests (urea, creatinine, electrolytes, calcium, phosphate, total protein, albumin, uric acid, alkaline phosphatase, total cholesterol, triglycerides, HDL and LDL cholesterol, intact parathormone (iPTH) and ferritin), complete blood count, and FGF23 levels were measured. Calcium, phosphate, protein and creatinine levels in 24 hour urine samples of all patients with chronic renal failure (CRF) except ones under dialysis were measured. Electrocardiograms and coronary CTs of patients were obtained after blood tests. Blood samples were taken; ECG and coronary CTs were obtained between dialysis sessions during the work days in patients undergoing hemodialysis while on the same day or the day after blood tests in patients followed-up at the outpatient clinics.

Data were analyzed, differences between groups were compared and relationship between FGF23 and biochemical parameters, left ventricle mass index, coronary and aortic calcification were investigated.

\section{Biochemical Analysis}

Venous blood samples were drawn after an overnight fast. Urea, creatinine, electrolytes, calcium, phosphate, total protein, albumin, uric acid, alkaline phosphatase levels were measured with Olympos AU 2700 autoanalyzer device at the Central Chemistry Laboratory of Sisli Etfal Education and Research Hospital. Ferritin and iPTH levels were measured with Advia Centaur XP device, with chemiluminescence immunoassay method.

\section{FGF23 Measurement}

Blood samples were taken into tubes containing EDTA. Serum was separated by centrifugating at 5000 $\mathrm{rpm}$ for 5 minutes. The samples were put into epandorf tubes, stored at $-80^{\circ} \mathrm{C}$ until the ELISA tests were done. Human FGF23 ELISA kit was used with polyclonal antibody sandwich ELISA method. Enzyme activity was measured spectrophotometrically. Numeric values of the samples were determined from corresponding absorbance values at the standards chart.

\section{Echocardiographic Assessment}

Transthoracic 2D echocardiographic assessments were done by the same cardiologist, with a GE Vivid 3 device using a 2,5 - 3,5 MHz transducer, at M mode parasternal long-axis and apical four-chamber windows. Diameter of the left atrium (LA), thickness of interventricular septum (IVS), thickness of the posterior wall of the left ventricle, end-diastolic and systolic diameters of left ventricle, and ejection fraction were measured. Left ventricle muscle mass was measured with Devereux RB formula, according to the recommendation of the American Society of Echocardiography [12] as below.

LV mass $($ Penn $)=1.04([L V I D D+P W T D+I V S T D] 3-[L V I D D] 3)-13,7 \mathrm{~g}$

Left ventricle mass index (LVMI) was measured by dividing left ventricle muscle mass to body surface area. DuBois formula was used in calculation of body surface area.

$B S A=\left(W^{0.425} \times H^{0.725}\right) \times 0.007184$

Left ventricle mass index $>131 \mathrm{~g} / \mathrm{m} 2$ in males and $>104 \mathrm{~g} / \mathrm{m} 2$ in females were considered as left ventricle hypertrophy.

\section{Coronary Artery Calcium Scoring}

Coronary artery calcium (CAC) scoring of the patients was done with Siemens Somatom Sensation 64 Slice multidetector computerized tomography (MDCT). The heart was scanned in the cranio-caudal direction during evaluation, from carina to the apex. The assessment parameters were used with a calibration factor of 0,788 . Coronary calcium scoring was done as described by Agatston et al. [13], with a threshold of 130 HU. A CAC score of $\leq 10$ was accepted as "minimal", 11-100 as "mild", $101-400$ as "moderate" and $>400$ as "serious" calcification, according to the calcium scoring guidelines. Calcification was considered as present in patients with coronary artery calcium score of 101 and above.

\section{Statistical Analysis}

Statistical Package for Social Sciences (SPSS) for Windows 18.0 software was used in the statistical analysis of data. Parametric variables were presented as mean \pm standard deviations. Categorical variables 


\section{Kidney Blood Pressure Research}

Kidney Blood Press Res 2012;36:55-64

\begin{tabular}{l|l} 
DOI: $10.1159 / 000339026$ & $\begin{array}{l}\text { C } 2012 \text { S. Karger AG, Basel } \\
\text { www.karger.com/kbr }\end{array}$
\end{tabular}

Published online: August 06, 2012 www.karger.com $/ \mathrm{kbr}$ Unsal/Kose Budak/Koc et al.: Relationship of FGF-23 with LVMI, Coronary Calcification
in CKD

Table 1. Sociodemographic characteristics of the patients

\begin{tabular}{|c|c|c|c|c|c|c|}
\hline & $\begin{array}{l}\text { Group } 1 \\
(n=30)\end{array}$ & $\begin{array}{l}\text { Group } 2 \\
(n=14)\end{array}$ & $\begin{array}{l}\text { Group } 3 \\
(n=21)\end{array}$ & $\begin{array}{l}\text { Group } 4 \\
(n=22)\end{array}$ & $\begin{array}{l}\text { Group } 5 \\
(n=71)\end{array}$ & $\mathrm{P}$ \\
\hline Duration of disease (months) & $29 \pm 28$ & $31 \pm 38,5$ & $26,6 \pm 15,5$ & $32 \pm 27,5$ & $70 \pm 46$ & 0,000 \\
\hline Age (years) & $52 \pm 12$ & $60 \pm 10$ & $61,8 \pm 12$ & $62,4 \pm 12$ & $46,2 \pm 14$ & 0,000 \\
\hline Gender (F/M) (n:101/57) & $21 / 9$ & $10 / 4$ & $14 / 7$ & $16 / 9$ & $40 / 31$ & 0,493 \\
\hline Diabetes (\%31.6) (n:50) & 43,3 & 35,7 & 61,9 & 26 & 8,5 & 0001 \\
\hline History of smoking (\%24.2) (n:38) & 43,3 & 28,6 & 14,3 & 18,2 & 20 & 0,079 \\
\hline Presence of LVH (n:44) & $\% 10$ & $\% 14,2$ & $\% 23,8$ & $\% 31,8$ & $\% 38$ & 0,04 \\
\hline Coronary artery calcification score & $62 \pm 173$ & $89 \pm 166$ & $128 \pm 254$ & $348 \pm 937$ & $508 \pm 1.831$ & 0,001 \\
\hline $\begin{array}{l}\text { Presence of coronary arterial } \\
\text { calcification }(\mathrm{n}: 18)(\%)\end{array}$ & 3,3 & 7,1 & 9,5 & 18,1 & 14,1 & 0,438 \\
\hline Aortic calcification (n:40) (\%) & 6,6 & 14,3 & 28,5 & 31,8 & 32,4 & 0,063 \\
\hline Valve calcification (n:19) & 0 & 0 & 14,3 & 18,2 & 16,9 & 0,075 \\
\hline
\end{tabular}

Table 2. Laboratory data of the patients according to groups

\begin{tabular}{|c|c|c|c|c|c|c|}
\hline & $\begin{array}{r}\text { Group 1 } \\
(\mathrm{n}=30)\end{array}$ & $\begin{array}{r}\text { Group 2 } \\
(\mathrm{n}=14)\end{array}$ & $\begin{array}{r}\text { Group } 3 \\
(\mathrm{n}=21)\end{array}$ & $\begin{array}{r}\text { Group } 4 \\
(\mathrm{n}=22)\end{array}$ & $\begin{array}{c}\text { Group } 5 \\
(\mathrm{n}=71)\end{array}$ & $P$ \\
\hline $\mathrm{GFR}\left(\mathrm{mL} / \mathrm{min} / 1.73 \mathrm{~m}^{2}\right)$ & $77,12 \pm 20,83$ & $51,15 \pm 5,07$ & $38,13 \pm 4,38$ & $23,04 \pm 4,67$ & $6,98 \pm 2,69$ & $<0,001$ \\
\hline Creatinine $(\mathrm{mg} / \mathrm{dL})$ & $0,93 \pm 0,15$ & $1,25 \pm 0,16$ & $1,65 \pm 0,28$ & $2,58 \pm 0,62$ & $8,46 \pm 2,48$ & $<0,001$ \\
\hline Albumin $(\mathrm{g} / \mathrm{dl})$ & $4,28 \pm 0,5$ & $4,24 \pm 0,3$ & $4,35 \pm 0,3$ & $4,13 \pm 0,4$ & $3,77 \pm 0,3$ & $<0,001$ \\
\hline Hemoglobin (g/dl) & $13,1 \pm 1,9$ & $13 \pm 1,5$ & $12,8 \pm 1$ & $11,4 \pm 1,5$ & $11,3 \pm 1,6$ & $<0,001$ \\
\hline Uric acid (mg/dl) & $6,0 \pm 2,4$ & $6,4 \pm 1,3$ & $7,0 \pm 1,2$ & $7,9 \pm 1,6$ & $5,7 \pm 1,3$ & $<0,001$ \\
\hline Calcium (mg/dL) & $9,52 \pm 0,56$ & $9,80 \pm 0,38$ & $9,85 \pm 0,43$ & $9,34 \pm 0,78$ & $9,18 \pm 0,87$ & $<0,001$ \\
\hline Phosphate (mg/dL) & $3,41 \pm 0,54$ & $3,24 \pm 0,41$ & $3,48 \pm 0,49$ & $3,98 \pm 0,85$ & $4,76 \pm 1,41$ & $<0,001$ \\
\hline CaxP & $32,31 \pm 4,65$ & $31,77 \pm 4,13$ & $34,21 \pm 4,66$ & $37,07 \pm 7,94$ & $43,67 \pm 13,11$ & $<0,001$ \\
\hline PTH $(\mathrm{pg} / \mathrm{mL})$ & $51,12 \pm 21,89$ & $93,86 \pm 66,18$ & $99,27 \pm 46,46$ & $209,46 \pm 189,38$ & $608,34 \pm 551,87$ & $<0,001$ \\
\hline FGF-23 (pg/mL) & $32,27 \pm 70,99$ & $100,39 \pm 175,79$ & $183,21 \pm 233,11$ & $285,40 \pm 576,97$ & $723,28 \pm 841,63$ & $<0,001$ \\
\hline $\operatorname{LVMI}\left(\mathrm{g} / \mathrm{m}^{2}\right)$ & $95,94 \pm 16,52$ & $94,71 \pm 17,08$ & $114,36 \pm 27,13$ & $119,33 \pm 38,68$ & $132,90 \pm 36,82$ & $<0,001$ \\
\hline $\begin{array}{l}\mathrm{FGF}-23(\mathrm{pg} / \mathrm{mL}) \\
\text { (presence of LVH) }\end{array}$ & $38,8 \pm 8,51$ & $80,78 \pm 10,51$ & $154,47 \pm 130,32$ & $367,20 \pm 749,37$ & $630,20 \pm 765,10$ & 0,006 \\
\hline
\end{tabular}

were summarized as number and percentage. Conformity of parametric data with the normal distribution was analyzed with Kolmogorov-Smirnov, Shapiro Wilks test. Homogeneity of variances was tested with t-test and One-Way ANOVA test. Differences between groups were evaluated with non-parametric Mann Whitney U and Kruskal - Wallis tests in series without a normal distribution. Chi-square test was used in the comparison of categorical variables. Pearson and Spearman's analysis were used in the analysis of correlation between the data. Non-normally distributed variable FGF-23 was also log-transformed to achieve a normal distribution and used in subsequent statistical analysis. $\mathrm{p}<0.05$ was considered as significant.

\section{Results}

Totally 158 patients (101 females) were included in this study. Their mean age was $53 \pm 14$, and the mean duration of disease was $48 \pm 42$ months. Mean BMI of the patients was $26.7 \pm 5.6 \mathrm{~kg} / \mathrm{m}^{2}$, and systolic and diastolic blood pressures were $129 \pm 20 \mathrm{~mm} \mathrm{Hg}$ and $80 \pm 12 \mathrm{~mm} \mathrm{Hg}$, respectively. Sociodemographic data of the patients are presented in Table 1. Biochemical data of the groups are presented in Table 2.

Causes of renal failure were diabetes in 50 patients, hypertension in 61 patients, chronic glomerulonephritis in 24 patients, reflux nephropathy in 5 patients and, undetermined etiology in 18 patients. Thirty six of the 50 patients (31.6\%) with diabetes were using insulin, 12 were using oral antidiabetic drugs (OAD), and 2 patients were using combination of OAD and insulin. Sixty-one patients (38.6\%) were using antihypertensive medications; 19 angiotensin receptor blockers (ARBs), 9 angiotensin converting enzyme inhibitors (ACE-i), 5 calcium channel blockers (CCBs), 13 combination therapy (CCB, ACE-i, ARB) and 15 beta blockers and/or diuretics.

Eight patients were taking sevelamer $\mathrm{HCl}$, and 37 phosphate binder containing calcium. Fifty-three patients were taking active $\mathrm{D}$ vitamin and 4 were taking cinacalcet. Twenty-eight patients were using an erythropoietin preparation. 


\section{Kidney Blood Pressure Research}

Table 3. FGF23 levels according to presence of $\mathrm{LVH}$ or not
Kidney Blood Press Res 2012;36:55-64

\begin{tabular}{l|l}
\hline DOI: $10.1159 / 000339026$ & (C) 2012 S. Karger AG, Basel
\end{tabular}

Published online: August 06, 2012

www.karger.com/kbr in CKD

\begin{tabular}{lccc}
\hline & With LVH (n:44) & Without LVH (n:114) & $\mathrm{p}$ \\
\hline Group 1 (n:3/27) & $38,8 \pm 8,51$ & $34.4 \pm 92.12$ & 0.53 \\
Group 2 (n:2/12) & $80,78 \pm 10,51$ & $110.2 \pm 185,8$ & 0.82 \\
Group 3 (n:5/16) & $154,47 \pm 130,32$ & $185.4 \pm 220.2$ & 0.64 \\
Group 4 (n:7/15) & $367,20 \pm 749,37$ & $274.4 \pm 356.2$ & 0.021 \\
Group5 (n:27/44) & $630,20 \pm 765,10$ & $735.33 \pm 845.2$ & 0.24 \\
\hline
\end{tabular}

Table 4. FGF23 levels according to presence of calcification or not

\begin{tabular}{lccccccccc}
\hline & \multicolumn{2}{c}{ Coronary artery calcification } & \multicolumn{3}{c}{ Aortic calcification } & & \multicolumn{3}{c}{ Valvular calcification } \\
& With & Without & p & With & Without & p & With & Without & p \\
\hline $\begin{array}{c}\text { Group } \\
1-3\end{array}$ & $134.2 \pm 205.2$ & $120.45 \pm 178.3$ & 0.86 & $143.2 \pm 160.2$ & $126.8 \pm 230.3$ & 0.42 & $170.1 \pm 363.1$ & $140.5 \pm 237.3$ & 0.12 \\
$\begin{array}{c}\text { Group } \\
4\end{array}$ & $188.2 \pm 194.2$ & $290.6 \pm 650.3$ & 0.53 & $356.3 \pm 657.3$ & $275.1 \pm 756.2$ & 0.12 & $324.5 \pm 450.4$ & $275.8 \pm 783.2$ & 0.052 \\
$\begin{array}{l}\text { Group } \\
5\end{array}$ & $788.4 \pm 546.4$ & $720.2 \pm 862.8$ & 0.76 & $746.5 \pm 844.2$ & $689.6 \pm 876.2$ & 0.36 & $846.2 \pm 680.1$ & $737.3 \pm 893.3$ & 0.17 \\
\hline
\end{tabular}

Left ventricular hypertrophy (LVH) was detected in $27.8 \%$ of patients $(n=44)$. LVH was determined in 3 patients at group 1, 2 patients at group 2 while it was present in 5, 7, and 27 patients at groups 3,4, and 5, respectively.

Aortic calcification was present in $40(25.3 \%)$ patients ( 2 patients in group 1,2 patients in group 2, 6 patients in group 3, 7 and 23 patients in groups 4 and 5, respectively). Vascular calcification was determined in $12 \%(n=19)$ of patients. It was not present in groups 1 and 2 while determined in 3, 4, and 12 patients in groups 3, 4, and 5, respectively. Coronary artery calcification (CAC > 100) was detected in $18(11.4 \%)$ patients. It was present in 1 patient at group 1 and 2, 2 patients in group 3. In groups 4 and 5, 4 and 10 patients had CAC, respectively.

FGF23 levels of patients with LVH or not were shown in Table 3. Presence of calcification (aortic, valvular, coronary artery) was present in a few patients at groups 1,2, and 3. Because of this, relation between presence of calcification and fgf 23 levels in patients among groups $1-3$, group 4, group 5 were shown in Table 4.

Negative relationship between LVMI and GFR (r: -0.266, p:0.001), serum albumin (r:-0.177, p: 0.030), calcium level (r:-0.196, p:0.015), and positive relationship with serum phosphate level (r:0.193, p:0.017), iPTH ( $\mathrm{r}: 0.295, \mathrm{p}<0.001)$, presence of hypertension ( $\mathrm{r}: 0.261, \mathrm{p}: 0.001)$, history of smoking ( $\mathrm{r}: 0.166, \mathrm{p}: 0.042)$, coronary artery calcification ( $r: 0.249$, p:0.046) and aortic calcification (r:0.300, p:0.016) were found in univariate analysis. No correlation was found between LVMI and $\log _{\mathrm{FGF} 23}$ (r:0.059, p:0.484).

There was a negative relationship between LVH and GFR (r:-0.199, p:0.014), serum albumin (r:-0.275, p:0.001), calcium (r:-0.193, p:0.017), hemoglobin level (r:-0.202, p:0.013), and a positive relationship with serum iPTH (r:0.275,p:0.001) and coronary artery calcification (r:0.277, p:0.026). However, no correlation was found with $\log _{\mathrm{FGF} 23}(\mathrm{r}: 0.068$, p:0.420).

Relationship between coronary artery calcification and age (r:0.346, p:0.004), LVH (r:0.277, p:0.026), LVMI (r:0.249, p:0.046) and valve calcification (r:0.274, p:0.026) were found statistically significant. Correlation between coronary artery calcification and $\log _{\mathrm{FGF} 23}$ level was not significant statistically (r:0.051, p:0.694).

Negative relationship between aortic calcification and GFR ( $\mathrm{r}:-0.753, \mathrm{p}<0.001)$, history of smoking (r:-0.265, p:0.030), and positive relationship with age (r:0.384, p:0.001), calcium (r:0.292, p:0.017), serum PTH (r:0.247, p:0.044), LVMI (r:0.300, :0.016) were found. There was no statistically significant relationship with $\log _{\mathrm{FGF} 23}$ level (r:0.064, p:0617).

Correlation between valve calcification and age (r:0.373, p:0.002), coronary artery calcification ( $\mathrm{r}: 0.274, \mathrm{p}: 0.026), \log _{\mathrm{FGF} 23}$ ( $\mathrm{r}: 0.276, \mathrm{p}: 0.029$ ) were detected statistically significant. 


\section{Kidney Blood Pressure Research}

Kidney Blood Press Res 2012;36:55-64

\begin{tabular}{l|l} 
DOI: $10.1159 / 000339026$ & $\begin{array}{l}\text { O } 2012 \text { S. Karger AG, Basel } \\
\text { www.karger.com/kbr }\end{array}$ \\
\hline
\end{tabular}

Published online: August 06, 2012

www.karger.com/kbr in CKD

Table 5. Linear univariate analysis of the relationship between $\log _{\mathrm{FGF} 23}$ and biochemical variables

\begin{tabular}{lcc}
\hline & $\mathrm{R}$ & $\mathrm{P}$ \\
\hline GFR & $-0,610$ & 0,000 \\
Phosphate & 0,392 & 0,000 \\
Calcium & 0,089 & 0,266 \\
Ca x P & 0,467 & 0,000 \\
Log PTH & 0,483 & 0,000 \\
Valve calcification & 0,276 & 0,029 \\
Presence of diabetes & 0,253 & 0,002 \\
\hline
\end{tabular}

Table 6. Linear multivariate analysis of the relationship between dependent variable $\log _{\mathrm{FGF} 23}$ and biochemical variables

\begin{tabular}{lcccc}
\hline & B & \multicolumn{2}{c}{$\begin{array}{c}95 \% \text { Confidence } \\
\text { interval for } \beta \\
\text { Lower level } \\
\text { of normal }\end{array}$} & $\begin{array}{c}\text { Upper level } \\
\text { of normal }\end{array}$ \\
\hline (Constant) & $-9,935$ & $-14,761$ & $-5,108$ & 0,000 \\
GFR & $-0,006$ & $-0,011$ & $-0,001$ & 0,000 \\
Phosphate & 1,479 & $-0,499$ & 2,459 & 0,000 \\
Calcium & 1,009 & 0,509 & 1,509 & 0,026 \\
Ca x P & $-0,133$ & $-0,240$ & $-0,026$ & 0,003 \\
Log PTH & 0,591 & 0,268 & 0,913 & 0,115 \\
\hline
\end{tabular}

Table 7. Comparison of linear univariate analysis of $\log _{\mathrm{FGF} 23}$ and biochemical variables of groups 1-3 and groups 4-5

\begin{tabular}{lcccc}
\hline & \multicolumn{2}{c}{ Groups 1-3 } & \multicolumn{2}{c}{ Groups 4-5 } \\
& $\mathrm{R}$ & $\mathrm{P}$ & $\mathrm{r}$ & $\mathrm{P}$ \\
\hline GFR & $-0,111$ & 0,378 & $-0,455$ & 0,000 \\
Phosphate & $-0,273$ & 0,028 & 0,474 & 0,000 \\
Calcium & 0,209 & 0,094 & 0,379 & 0,000 \\
Ca x P & $-0,216$ & 0,084 & 0,566 & 0,000 \\
Log & 0,023 & 0,858 & 0,279 & 0,007 \\
\hline
\end{tabular}

Statistically significant relationship between $\log _{\mathrm{FGF} 23}$ and GFR, serum phosphate, $\log _{\mathrm{PTH}}$, and CaxP, presence of diabetes and valve calcification was not detected. GFR, phosphate, calcium, $\mathrm{Ca} \times \mathrm{P}$ product were found to be predictors of $\log _{\mathrm{FGF} 23}$ in the multivariate analysis (Table 5 and 6).

When the values of different groups were compared (Table 2), FGF23 levels were observed to be deliberately higher in group $4-5\left(\mathrm{GFR}<30 \mathrm{~mL} / \mathrm{min} / 1.73 \mathrm{~m}^{2}\right)$. For this reason, data were stratified into two groups according to different GFR levels: groups 1-3, GFR $>30$ and groups $4-5$, GFR $<30$. Significant correlation was observed only between phosphate $(\mathrm{r}=-0.273, \mathrm{p}=0.028)$ and $\log _{\mathrm{FGF} 23}$ in groups 1-3. Correlation between $\log _{\mathrm{FGF} 23}$ and GFR, phosphate, calcium, $\mathrm{Ca} \times \mathrm{P}$ and $\log _{\mathrm{PTH}}$ in groups $4-5$ patients were statistically significant (Table 7).

\section{Discussion}

In this prospective, cross-sectional study, LVH was found in $27.8 \%$, aortic calcification in $25.3 \%$, valve calcification in $12 \%$ and coronary artery calcification in $11.4 \%$ of patients with chronic renal disease. LVMI and FGF23 levels were found to increase proportionally with the severity of renal failure, and they reach highest levels in patients under dialysis therapy. Correlation between $\log _{\mathrm{FGF}}$ and valve calcification was significant, whereas no statistically significant relationship was found between $\log _{\mathrm{FGF} 23}$ and LVMI, LVH, aortic and coronary artery calcifications.

Significant relationships were found between LVMI and coronary artery calcification and aortic calcification, between LVH and coronary artery calcification, and valve calcification and $\log _{\mathrm{FGF} 23}$ and coronary artery calcification. 


\section{Kidney
Blood Pressure Research}

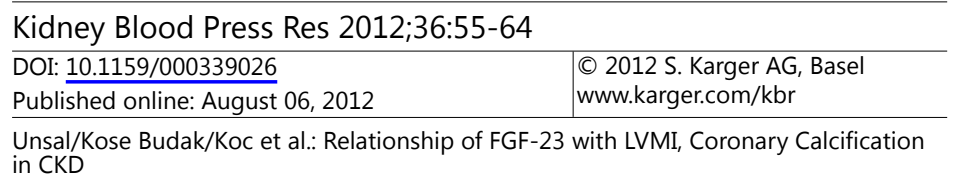

In subgroup analysis, there was significant correlation between $\log _{\text {FGF23 }}$ level and serum phosphate level in patients with a GFR of $\geq 30 \mathrm{~mL} / \mathrm{min}$. In addition, significant correlation was present between GFR, phosphate, calcium, Ca x P and $\log _{\text {PTH }}$ values in patients with GFR less than $30 \mathrm{~mL} / \mathrm{min}$.

FGF-23, a phosphaturic factor produced by osteoblasts, has emerged in the past decade as a major regulator of mineral metabolism in health and disease. Under physiological conditions, it acts as a circulating phosphaturic factor through suppression of proximal tubular $\mathrm{Na} / \mathrm{Pi}-2 \mathrm{a}$ and $\mathrm{Na} / \mathrm{Pi}-2 \mathrm{c}$ cotransporters [14-17]. In CKD, circulating FGF-23 levels gradually increase with declining renal function such that by the time patients reach endstage renal disease, FGF - 23 levels can be up to 1000-fold above the normal range [18]. The increase in FGF-23 begins at a very early stage of CKD as a physiological compensation to stabilize serum phosphate levels as the number of intact nephrons declines [19-21]. Since the plasma FGF-23 level is regulated by serum Pi [22, 23] and vica versa [24, 25], it appears that the plasma $\log _{\mathrm{FGF}-23}$ levels should be different between groups. In many studies, it was reported that there was a correlation between serum FGF-23 levels and serum creatinine, phosphate, Ca x P product, and parathormon levels [7, 20, 26, 27]. We also found a positive and significant relationship between $\log _{\mathrm{FGF}-23}$ levels and serum phosphate, $\log _{\mathrm{PTH}}$ and $\mathrm{Ca}$ $\mathrm{x} P$ product. This relationship was deliberate especially in patients with GFR less than $30 \mathrm{~mL} / \mathrm{min}$.

The relationship between vascular calcification and FGF-23 in CKD patients is more ambiguous; one recent study [28] reported an independent positive correlation between FGF-23 and peripheral vascular calcification, whereas another study [9] reported a negative association. Even less clear is the relation of FGF-23 to aortic calcification which, unlike peripheral calcification, is associated with coronary artery calcification. Aortic calcification was shown to be associated with coronary calcification [29] in CKD. The relationship between aortic calcification and FGF-23 was not demonstrated since preceding studies did not account for aortic calcification as a separate entity [28] or could not demonstrate a correlation with aortic calcification on lateral lumbar X-rays [9]. Inaba et al. [9] had reported that no relationship was present between plasma FGF23 levels and aortic calcification in patients with HD, but an association with peripheral vascular calcification was present. In this study, aortic vascular calcification was found in $41.1 \%$ and $65.6 \%$ of hemodialysis patients with and without DM, respectively. We detected aortic vascular calcification in $32.4 \%$ of our stage 5 patients. We could not find a correlation between aortic calcification and $\log _{\mathrm{FGF} 23}$ and coronary artery calsification. A possible explanation for the absence of correlation may be the low frequency of aortic calcification in especially stage 5 patients.

Correlation analysis revealed positive relationships between coronary artery calcium score and dialysis duration, $\mathrm{P}$ levels, and $\mathrm{Ca} \mathrm{x} \mathrm{P}$ products. In contrast, calcium score was inversely correlated with FGF-23 and BMI. FGF-23 showed a significant inverse correlation with CAC in univariate analysis but it was not an independent predictive factor of CAC in multivariate analysis [30]. Conversely, Roos et al. [31] reported no association between CAC and FGF-23 levels in patients with normal kidney function. In another study, Gutierrez et al. [7] reported that, in univariate analysis, increasing age, history of coronary artery disease and smoking were associated with a significantly increased risk of coronary artery calcification score. Serum phosphate concentrations were not associated with coronary artery calcification. On a continuous scale, increased $\log _{\mathrm{FGF}-23}$ concentrations were not significantly associated with $\log$ - transformed coronary artery calcification.

Besides this, an aortic VC score has been reported to be highly correlated with CAC [32]. We found a correlation between CAC and increasing age, LVH, LVMI and valve calcification in our patient, but we could not find a correlation with FGF-23. $\log _{\text {FGF-23 }}$ levels were found to be higher in HD patients with coronary artery disease and valve calcification in another study [26]. We also detected a correlation between the presence of valve calcification and $\log _{\text {FGF-23. }}$.

LVH was also associated with higher levels of FGF-23 in HD patients [8]. Poor control of serum phosphate level and the calcium - phosphorus product were known to be associated with increased left ventricular mass (LVM) [33]. An animal study found that hyperphosphatemia led to LVM increase in chronic renal failure model induced by five-sixths 


\section{Kidney \\ Blood Pressure Research}

\begin{tabular}{|c|c|}
\hline Kidney Blood Press Res 20 & \\
\hline DOI: $10.1159 / 000339026$ & $\begin{array}{l}\text { (C) } 2012 \text { S. Karger AG, Basel } \\
\text { www.karger.com/kbr }\end{array}$ \\
\hline
\end{tabular}

nephrectomy, parathyroidectomy, parathyroid hormone replacement, and high - phosphate diet [34]. This suggests that hyperphosphatemia may promote LVH by altering vascular reactivity or by inducing endothelial or vascular smooth muscle phenotypic changes and thereby changes the systemic vascular resistance and endothelial function. These studies all suggest that poor control of mineral metabolism plays a role in the pathogenesis of LVH in dialysis patients $[8,33,34]$. Univariate analysis showed that BMI, hypertension, serum phosphate levels, increased log FGF-23 concentrations and diabetes mellitus were significantly associated with LVMI but in the multivariate model, BMI and log FGF-23 were the only parameters that remained significantly associated with LVMI [26].

Higher FGF-23 levels were associated with mortality in persons with end-stage renal disease [35] and greater left ventricular mass in individuals with moderate to severe CKD [7]. We found highest levels of LVMI in our stage 5 patients. We also detected a correlation between LVMI and coronary artery calcification and aortic calcification, and LVH and coronary artery calcification. However, there was not a correlation with $\log _{\text {FGF-23 }}$. We found $\mathrm{LVH}$ in $28 \%$ of our patients, diabetes in $31.6 \%$, and hypertension in $38.6 \%$. The relatively small number of patients with hypertension and LVH may have played a role in not finding a correlation between LVMI and $\log _{\mathrm{FGF}-23}$.

There were several limitations of this prospective cross-sectional study. Due to the design of the study, we investigated echocardiographic parameters of left ventricular function and vascular calcification in which changes generally occur by time. Then, we tried to find out associations between these and single measurement of FGF-23 levels in certain time points. Uncertain possible variations may took place in plasma FGF-23 levels. Another important limitation of this study was the absence of serum $25(\mathrm{OH}) \mathrm{D}_{3}$ and 1,25 $(\mathrm{OH}) 2 \mathrm{D}_{3}$ level measurements. The inverse relationship between $1,25(\mathrm{OH}) 2 \mathrm{D}_{3}$ and FGF-23 is well known [36], and low vitamin D status (tissue or circulating levels, therefore high FGF-23 state) was associated with left ventricular hypertrophy and cardiovascular disorders [37, 38]. The prescription and supplementation of vitamin $D$ do not indicate the real vitamin $D$ status in especially stage 5 dialysis patients including HD and PD patients. Differences in disturbances of bone mineral metabolism that may be observed in HD and PD patients, and their possible effects on FGF-23 levels, LVH, LVMI and calcifications were ignored.

\section{Conclusion}

In CKD, circulating FGF-23 levels gradually increase with declining renal function such that by the time patients reach end-stage renal disease. A significant positive correlation between FGF-23 level and serum phosphate, $\log _{\text {PтH' }}$, and Ca x P product was found. While a correlation between FGF-23 and valve calcification was detected, no correlation could be detected with left ventricular muscle mass index, left ventricular hypertrophy, coronary and aortic calcification.

\section{Declaration of Interest statement}

There aren't any non-financial competing interests we would like to declare in relation to this paper. We haven't any other financial competing interests. 


\section{Kidney \\ Blood Pressure Research}

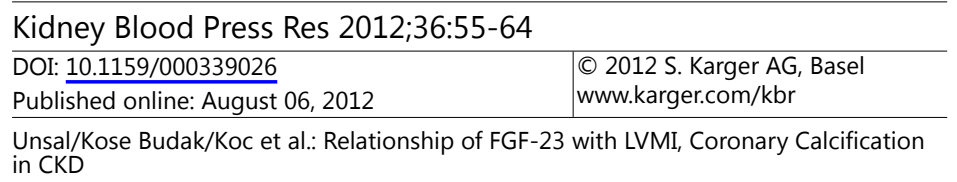

\section{References}

1 Best PJ, Holmes DR Jr: Chronic kidney disease as a cardiovascular risk factor. Am Heart J 2003;145:383386.

2 Tonelli M, Sacks F, Pfeffer M, Gao Z, Curhan G: Cholesterol And Recurrent Events Trial Investigators. Relation between serum phosphate level and cardiovascular event rate in people with coronary disease. Circulation 2005;112:2627-2633.

-3 Schwarz S, Trivedi BK, Kalantar-Zadeh K, Kovesdy CP: Association of disorders in mineral metabolism with progression of chronic kidney disease. Clin J Am Soc Nephrol 2006;1:825-831.

-4 Voormolen N, Noordzij M, Grotendorst DC, Beetz I, Sijpkens YW, van Manen JG, Boeschoten EW, Huisman RM, Krediet RT, Dekker FW, PREPARE study group: Hýgh plasma phosphate as a risk factor for decline in renal function and mortality in pre- dialysis patients. Nephrol Dial Transplant 2007;22:2909-2916.

-5 Rodriguez M, Felsenfeld AJ: PTH, FGF-23 and early CKD. Nephrol Dial Transplant 2008;23:3391-3393.

6 Fliser D, Kollerits B, Neyer U, Ankerst DP, Lhotta K, Lingenhel A, Ritz E, Kronenberg F, MMKD Study Group, Kuen E, König P, Kraatz G, Mann JF, Müller GA, Köhler H, Riegler P: Fibroblast growth factor 23 (FGF23) predicts progression of chronic kidney disease: the mild to moderate kidney disease study. J Am Soc Nephrol 2007;18:2601-2608.

-7 Gutierrez OM, Januzzi JL, Isakova T, Laliberte K, Smith K, Collerone G, Sarwar A, Hoffmann U, Coglianese E, Christenson R, Wang TJ, deFilippi C, Wolf M: Fibroblast growth factor 23 and left ventricular hypertrophy in chronic kidney disease. Circulation 2009;119:2545-2552.

8 Hsu HJ, Wu M: Fibroblast growth factor 23: A possible cause of left ventricular hypertrophy in hemodialysis patients. Am J Med Sci 2009;337:116-122.

\$ Inaba M, Okuno S, Imanishi Y, Yamada S, Shioi A, Yamakawa T, Ishimura E, Nishizawa Y: Role of fibroblast growth factor-23 in peripheral vascular calcification in non-diabetic and diabetic hemodialysis patients. Osteoporos Int 2006;17:1506-1513.

$>10$ Chobanian AV, Bakris GL, Black HR, Cushman WC, Green LA, Izzo JL Jr, Jones DW, Materson BJ, Oparil S, Wright JT Jr, Roccella EJ; Joint National Committee on Prevention, Detection, Evaluation, and Treatment of High Blood Pressure. National Heart, Lung, and Blood Institute: National High Blood Pressure Education Program Coordinating Committee. Seventh report of the Joint National Committee on Prevention, Detection, Evaluation, and Treatment of High Blood Pressure. Hypertension 2003;42:1206-1252.

-11 National Kidney Foundation: K/DOQI Clinical Practice Guidelines for Chronic Kidney Disease Evaluation, Classification, and Stratification. Am J Kidney Dis 2002;39:S76-S92.

12 Devereux RB, Reichek N: Echocardiographic determination of left ventricular mass in man. Anatomic validation of the method. Circulation 1977;55:613-18.

13 Agatston AS, Janowits WR, Hildner FJ, Zusmer NR, Viamonte M Jr, Detrano R: Quantification of Coronary Artary Calcium Using Ultrafast Computed Tomography. J M Coll Jardiol 1990;15:827-832.

-14 Imel EA, Econs MJ: Fibroblast growth factor 23: roles in health and disease. J Am Soc Nephrol 2005;16:2565-2575.

15 Razzaque MS: Does FGF23 toxicity influence the outcome of chronic kidney disease? Nephrol Dial Transplant 2009;24:4-7.

16 Zoccali C: FGF-23 in dialysis patients: ready for prime time? Nephrol Dial Transplant 2009;24:1078-1081.

17 Miyamoto K, Ito M, Tatsumi S Kuwahata M, Segawa H: New aspect of renal phosphate reabsorption: the type IIc sodium-dependent phosphate transporter. Am J Nephrol 2007;27:503-515.

-18 Gutierrez O, Isakova T, Rhee E, Shah A, Holmes J, Collerone G, Jüppner H, Wolf M: Fibroblast growth factor23 mitigates hyperphosphatemia but accentuates calcitriol deficiency in chronic kidney disease. J Am Soc Nephrol 2005;16:2205-2215.

-19 Marsell R, Grundberg E, Krajisnik T, Mallmin H, Karlsson M, Mellström D, Orwoll E, Ohlsson C, Jonsson KB, Ljunggren O, Larsson TE: Fibroblast growth factor-23 is associated with parathyroid hormone and renal function in a population-based cohort of elderly men. Eur J Endocrinol 2008;158:125-129.

20 Larsson T, Nisbeth U, Ljunggren Ö, Jüppner H, Jonsson KB: Circulating concentration of FGF-23 increases as renal function declines in patients with chronic kidney disease, but does not change in response to variation in phosphate intake in healthy volunteers. Kidney Int 2003;64:2272-2279. 


\section{Kidney \\ Blood Pressure Research}

Kidney Blood Press Res 2012;36:55-64

\begin{tabular}{l|l}
\hline DOI: $10.1159 / 000339026$ & C 2012 S. Karger AG, Basel \\
Published online: August 06, 2012 & www.karger.com/kbr
\end{tabular}

Published online: August 06, 2012

www.karger.com/kbr

Unsal/Kose Budak/Koc et al.: Relationship of FGF-23 with LVMI, Coronary Calcification in CKD

-21 Fliser D, Kollerits B, Neyer U. Ankerst DP, Lhotta K, Lingenhel A, Ritz E, Kronenberg F; MMKD Study Group, Kuen E, König P, Kraatz G, Mann JF, Müller GA, Köhler H, Riegler P: Fibroblast Growth Factor 23 (FGF23) predicts progression of chronic kidney disease: the mild to moderate kidney disease (MMKD) study. J Am Soc Nephrol 2007;18:2600-2608.

-22 Imel EA, Econs MJ: Fibroblast growth factor 23: roles in health and disease. J Am Soc Nephrol 2005;16:2565-2575.

23 Gupta A, Winer K, Econs MJ, Marx SJ, Collins MT: FGF- 23 is elevated by chronic hyperphosphatemia. J Clin Endocrinol Metab 2004;89:4489-4492.

-24 Yamashita T, Konishi M, Miyake A, Inui K, Itoh N: Fibroblast growth factor (FGF)-23 inhibits renal phosphate reabsorption by activation of the mitogen-activated protein kinase pathway. J Biol Chem 2002;277:28265-28270.

-25 Econs MJ, McEnery PT: Autosomal dominant hypophosphatemic rickets/osteomalacia: clinical characterization of a novel renal phosphate wasting disorder. J Clin Endocrinol Metab 1997;82:674-681.

-26 Kirkpantur A, Balci M, Gurbuz OA, Afsar B, Canbakan B, Akdemir R, Ayli MD: Serum fibroblast growth factor-23 (FGF-23) levels are independently associated with left ventricular mass and myocardial performance index in maintenance haemodialysis patients. Nephrol Dial Transplant 2011;26:1346-1354.

27 Olauson H, Qureshi AR, Miyamoto T, Barany P, Heimburger O, Lindholm B, Stenvinkel P, Larsson TE: Relation between serum fibroblast growth factor-23 level and mortality in incident dialysis patients: are gender and cardiovascular disease confounding the relationship? Nephrol Dial Transplant 2010;25:30333038.

28 Jean G, Bresson E, Terrat JC, Vanel T, Hurot JM, Lorriaux C, Mayor B, Chazot C: Peripheral vascular calcification in long-haemodialysis patients: associated factors and survival consequences. Nephrol Dial Transplant 2009;24:948-955.

-29 Bellasi A, Ferramosca E, Muntner P Ratti C, Wildman RP, Block GA, Raggi P: Correlation of simple imaging tests and coronary artery calcium measured by computed tomography in hemodialysis patients. Kidney Int 2006;70:1623-1628.

-30 Cianciolo G, La Manna G, Donati G, Persici E, Dormi A, Cappuccilli ML, Corsini S, Fattori R, Russo V, Nastasi V, Colì L, Wratten M, Stefoni S: Coronary calcifications in end-stage renal disease patients: a new link between osteoprotegerin, diabetes and body mass index? Blood Purif 2010;29:13-22.

- 31 Roos M, Lutz J, Salmhofer H, Luppa P, Knauss A, Braun S, Martinof S, Schömig A, Heemann U, Kastrati A, Hausleiter J: Relation between plasma fibroblast growth factor-23, serum fetuin-A levels and coronary artery calcification evaluated by multislice computed tomography in patients with normal kidney function. Clin Endocrinol 2008;68:660-665.

-32 Raggi P: Detection and quantification of cardiovascular calcifications with electron beam tomography to estimate risk in hemodialysis patients. Clin Nephrol 2000;54:325-333.

-33 Strozecki P, Adamowicz A, Nartowicz E, Odrowaz-Sypniewska G, Włodarczyk Z, Manitius J: Parathormon, calcium, phosphorus, and left ventricular structure and function in normotensive hemodialysis patients. Ren Fail 2001;23:115-126.

34 Neves KR, Graciolli FG, dos Reis LM, Pasqualucci CA, Moysés RM, Jorgetti V: Adverse effects of hyperphosphatemia on myocardial hypertrophy, renal function, and bone in rats with renal failure. Kidney Int 2004;66:2237-2244.

-35 Gutierrez OM, Mannstadt M, Isakova T Rauh-Hain JA, Tamez H, Shah A, Smith K, Lee H, Thadhani R, Jüppner $\mathrm{H}$, Wolf M: Fibroblast growth factor 23 and mortality among patients undergoing hemodialysis. N Engl J Med 2008;359:584-592.

36 Saito H, Kusano K, Kinosaki M, Ito H, Hirata M, Segawa H, Miyamoto K, Fukushima N: Human fibroblast growth factor-23 mutants suppress Na+-dependent phosphate co-transport activity and 1alpha,25dihydroxyvitamin D3 production. J Biol Chem 2003;278:2206-2211.

-37 Achinger SG, Ayus JC: The role of vitamin D in left ventricular hypertrophy and cardiac function. Kidney Int Suppl 2005;95:S37-S42.

-38 Artaza JN, Mehrotra R, Norris KC: Vitamin D and the cardiovascular system. Clin J Am Soc Nephrol 2009;4:1515-1522. 